\title{
MONTE CARLO STUDY OF HOLDING FORCES FOR TANK CARS ON GRADES
}

\author{
J. Karl Alexy \\ Office of Safety \\ Federal Railroad Administration \\ US Department of Transportation \\ Washington, DC USA \\ David Y. Jeong \\ Volpe National Transportation Systems Center \\ Research and Innovative Technology Administration \\ US Department of Transportation \\ Cambridge, Massachusetts, USA \\ Francisco González III \\ Office of Research and Development \\ Federal Railroad Administration \\ US Department of Transportation \\ Washington, DC USA
}

\section{ABSTRACT}

This paper describes a numerical procedure to examine the holding forces needed to secure a cut of railroad tank cars staged on a grade during loading and unloading operations. Holding forces are created by applying emergency brake systems and blocking (or chocking) wheels. Moreover, the holding force to secure the cut of cars must be greater than or equal to the gravitational component of force acting on the cars that is parallel to the grade. Engineering statics are applied to examine the forces acting on the individual cars resting on an inclined plane. An equation to calculate holding force is developed that includes two types of factors: constants (i.e. nonrandom or deterministic factors) and probabilistic variables (i.e. factors with inherent uncertainty or randomness). The numerical procedure applies Monte Carlo simulation techniques to study the uncertainties in the engineering analysis. The Monte Carlo approach is well suited to study the uncertainties and inherent variability associated with some of these factors. The factors assumed to be deterministic in this procedure are: steepness of the grade, total number of cars on the grade, number of cars with hand brakes applied, number of chocked wheels, and weight of the tank cars. The factors treated as random variables are: tension in the hand brake chain,
\end{abstract}

mechanical efficiency in the linkages of the brake system, coefficient of friction between the brake pad and the wheel, and the coefficient of friction between the chocks and the rail. Probability distributions are assumed for each of the random variables. In addition, a probabilistic sensitivity analysis is conducted to examine the relative effect of the random variables on the reliability of the braking system to secure the cut of tank cars on a grade.

\section{INTRODUCTION}

Hazardous Materials Regulations (HMR) issued by the U.S. Department of Transportation (US DOT), Pipeline and Hazardous Materials Safety Administration (PHMSA) govern the transportation of hazardous materials by highway, rail, vessel and air. Regulations for loading and unloading operations of railroad tank cars carrying hazardous materials are specified in Title 49 of the Code of Federal Regulations (CFR) $\$ 174.67$ [1]. Prior to 2005 , the regulations required that the hand brakes on all cars positioned at loading/unloading racks be set. In 2005, a final rule (HM-233) was published by PHMSA and the Federal Railroad Administration (FRA) regarding loading and unloading operations for hazardous materials [2]. With the promulgation of this final rule, the regulations were

This material is declared a work of the U.S. Government and is not subject to copyright protection in the United States. Approved for public release; distribution is unlimited. 
changed, and currently states that "sufficient hand brakes must be set and wheels blocked to prevent movement in both directions."

Federal law authorizes DOT to issue variances - called special permits - to allow the grantee to package or ship hazardous material in a manner that varies from the HMR provided an equivalent level of safety is maintained. Special permits provide a mechanism for testing new technologies, promoting increased transportation efficiency and productivity, and ensuring global competitiveness. Long standing special permits with an established safety record are often incorporated into the regulations. Revisions to the regulations based on special permits are intended to provide wider access to the regulatory flexibility offered in special permits and to eliminate the need for numerous renewal requests, thus reducing paperwork burdens and facilitating commerce while maintaining an appropriate level of safety. Special permits, however, contain detailed language to stipulate safety control measures and special provisions while the wording of the regulations is generic.

In the case of hazardous materials transportation by rail, FRA evaluates the provisions and the terms of special permits, and subsequently provides recommendations to PHMSA. One of the purposes of the present work is to understand the requirements for holding forces of coupled cars on a grade. The results presented in this paper may provide technical information to support future rulemaking activities and amendments to the CFR regarding loading and unloading operations of railroad tank cars carrying hazardous materials proposed by PHMSA and FRA.

This paper describes a probabilistic approach to evaluate braking requirements for a specified number of coupled cars on grades between $0.5 \%$ and $1.0 \%$. The approach is based on applying engineering statics to examine the forces acting on the individual tank cars, which are represented by objects resting on an inclined plane. The holding force needed to offset the gravitational component parallel to the slope is calculated to prevent movement on a given grade. The equations developed from engineering statics are combined with a basic working knowledge of probability and statistics to develop a Monte Carlo model to evaluate the probability of impending motion. That is, Monte Carlo simulations are carried out in which the factors affecting the performance of the hand brake system are treated as random variables with assumed probability distributions characterized by their mean values and standard deviations. The Monte Carlo method is well suited to study uncertainties and the inherent variability in the factors considered in the analysis. In addition, probabilistic sensitivity analysis is performed to examine the relative effect of each factor on the holding force needed to secure the tank cars parked on a grade. This probabilistic approach has been applied previously to examine the sensitivity of various factors on the conditional probability of release of hazardous materials from railroad tank cars during accidents [3].

\section{MONTE CARLO APPROACH}

In Monte Carlo simulations, each random variable is sampled several times to represent its distribution according to its probabilistic or statistical characteristics. The Monte Carlo simulation technique consists of the following essential elements [4]:

1. Defining the problem in terms of random variables,

2. Quantifying the probabilistic characteristics of the random variables in terms of their probability distribution functions and the corresponding parameters,

3. Generating values of the these random variables,

4. Exercising numerical simulations, and

5. Extracting probabilistic information from the number of simulations that are carried out.

These elements as developed for the present application are described in the following sections.

\section{Problem Formulation}

Figure 1 shows a free-body diagram with forces acting on an object resting on an inclined plane. The gravitational force acting on the object in the direction that is parallel to the slope is:

$$
f_{x}=W \sin \theta
$$

where $W$ is the weight of the body and $\theta$ is the angle of the inclined plane in radians. The static frictional force required to prevent the object from sliding is

$$
f_{s}=\mu_{s} N=\mu_{s} W \cos \theta
$$

where $\mu_{s}$ is the coefficient of static friction and $N$ is the normal force. A critical slope for sliding friction, called the angle of repose, may be calculated by combining these two equations:

$\theta_{\text {crit }}=\tan ^{-1} \mu_{s}$

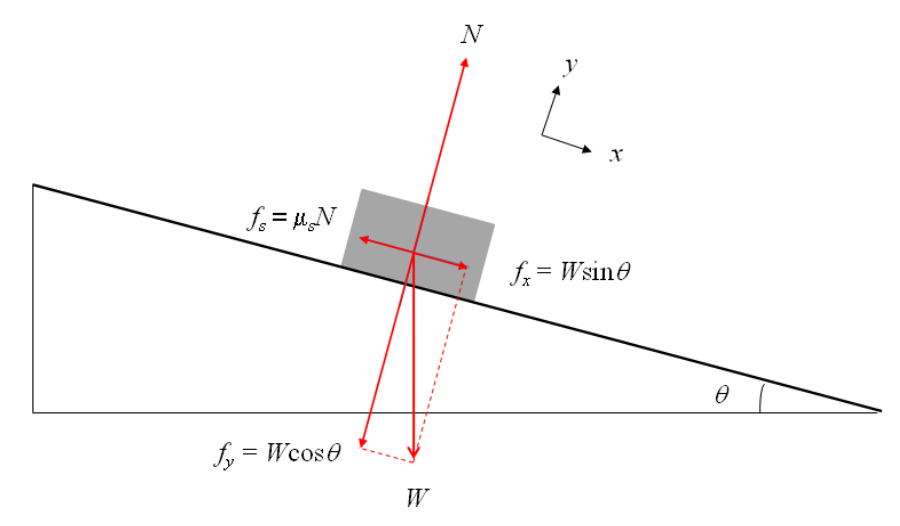

Figure 1: Forces Acting on Object Resting on Inclined Plane 
The angle of repose is the angle to which an inclined plane may be raised before an object resting on it will move under the action of gravity and reaction of the plane. Moreover, the angle of repose is independent of the weight of the object. Assuming a value of 0.3 for the coefficient of static friction, corresponding to the value for steel sliding on steel, the angle of repose as calculated from equation (3) is equal to $16.7^{\circ}$ or a grade of $30 \%$. Because the grades under consideration in this paper (between $0.5 \%$ and $1.0 \%$ ) are less than the angle of repose, a cut of tank cars on a grade will be secured from movement by sliding provided that sufficient hand brakes and wheel blocks are applied. Therefore, the problem is formulated to determine the number of hand brakes and blocked wheels (also referred to as chocked wheels) to secure the cut of tank cars on a given grade from movement by rolling.

Figure 2 shows a schematic for a cut of tank cars on a grade. The gravitational force parallel to the slope for each car is:

$$
f_{w}=W \sin \theta
$$

where $W$ is the weight of each tank car (assumed to be the same for each car) and $\theta$ is the angle of the slope in radians. Throughout this study, the tank car weight is kept constant. Unless specified otherwise, the tank car weight is equal to the maximum gross rail load of 286,000 pounds. The total gravitational force parallel to the slope for the cut of cars on the grade is

$$
F_{w}=\sum^{N} f_{w}=N f_{w}=N W \sin \theta
$$

where $N$ is the number of cars on the grade.

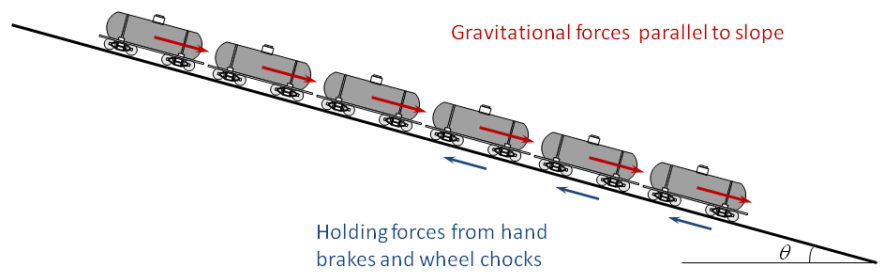

\section{Figure 2: Cut of Tank Cars Parked on Grade}

The total holding force is created by the hand brakes and wheel chocks, and acts opposite to the direction of the gravitational component of force parallel to the slope. Wheel chocks are required to be set in both directions on the first and last car. The braking force created by a single wheel chock is
$f_{c}=\mu_{c}\left(\frac{W}{8}\right) \cos \theta$

where $f_{c}$ is the braking force of the chock per wheel and $\mu_{c}$ is the coefficient of friction between the rail and the wheel chock. The weight of the chocked car is divided by 8 to represent the wheel load.

The braking (clamping of the brake pad to the wheel) force of the hand brake system is assumed to be proportional to the tension in the chain between the hand brake wheel and the linkages in the brake levers. A tank car builder indicated that the design criterion for the brake wheel support is $3,300 \mathrm{lb}$ of tension in the chain. In subsequent calculations, the braking force is assumed to be less than the 3,300 lb design force, and is calculated using:

$f_{b}=\varepsilon \mu_{b} T_{c}$

where $f_{b}$ is the braking force created by the hand brake per car, $\varepsilon$ is the mechanical efficiency in the linkages, $\mu_{b}$ is the coefficient of friction between the brake pad and the wheel, and $T_{c}$ is the initial tension in the hand brake chain.

The applied tension is proportional to the clamping force of the brake pad at the wheel. The proportionality coefficient is the inefficiencies of the linkages as well as the friction between the brake pad and wheel. This tension is distributed between four wheels of the truck at the B-end of the tank car. To simplify the calculations, it is assumed the braking force on the wheels connected by an axle is equal.

The total holding force is calculated from adding the applied hand brakes and the blocked or chocked wheels:

$F_{h}=\sum^{n} f_{b}+\sum^{m} f_{c}=n f_{b}+m f_{c}=n \varepsilon \mu_{b} T_{c}+m \mu_{c} \frac{W}{8} \cos \theta$

where $n$ is the number of cars with their hand brakes applied and $m$ is the number of wheel chocks.

Therefore, the cut of cars on the grade will be secured from movement if the total gravitational force parallel to the slope is less than or equal to the total holding force. Mathematically, the cars will remain in equilibrium if the following inequality is satisfied:

$F_{w} \leq F_{h}$

For grades between $0.5 \%$ and $1.0 \%$, the small-angle approximation is applied to equations (5) and (8). That is, for small angles, $\sin \theta \approx \theta$ and $\cos \theta \approx 1$. Moreover, for this range of grades:

$F_{w}=N W \theta$ 


$$
F_{h}=n \varepsilon \mu_{b} T_{c}+m \mu_{c} \frac{W}{8}
$$

For a given slope of the grade, the following factors are held constant: (1) the number of tank cars parked on the grade, $N$; (2) the number of cars with hand brakes applied, $n$; (3) the number of chocked wheels, $m$; and (4) weight of the tank cars, $W$. In this paper, four factors are treated as random variables: (1) the tension in the hand brake chain, $T_{c}$; (2) the efficiency in the linkage system, $\varepsilon$, (3) the coefficient of friction between the brake pad and the wheel, $\mu_{b}$; and (4) the coefficient of friction between the wheel chocks and the rail, $\mu_{c}$.

\section{Probabilistic Characteristics of Random Variables}

In general, the probability distribution and corresponding parameters for a random variable are estimated using available data. In the present engineering problem, the choice of probability distribution is based on mathematical convenience and basic familiarity with certain distributions.

Table 1 lists the random variables along with their assumed probability density functions and corresponding mean values and standard deviations (SD). The mean values are intended to represent average or typical values for each factor. The values of the standard deviations are representative of the uncertainties associated with each factor. These uncertainties and the choice of probability distribution are discussed below.
Table 1: Random Variables and Assumed Probability Distributions

\begin{tabular}{|l|c|c|c|}
\hline Random Variable & $\begin{array}{c}\text { Probability } \\
\text { Density } \\
\text { Function }\end{array}$ & $\begin{array}{c}\text { Mean } \\
\text { Value }\end{array}$ & $S D$ \\
\hline Tension, $T_{c}$ & Normal & 2000 & 200 \\
\hline Coefficient of friction, $\mu_{b}$ & Lognormal & 0.9 & 0.02 \\
\hline Coefficient of friction, $\mu_{c}$ & Lognormal & 0.2 & 0.02 \\
\hline Efficiency, $\varepsilon$ & Lognormal & 0.8 & 0.04 \\
\hline
\end{tabular}

The total holding force is calculated using equation (11). As shown schematically in Figure 3, the total holding force is a random variable with a probability distribution characterized by a mean value and a standard deviation. The gravitational force parallel to the slope is calculated from equation (10), and is constant (i.e. deterministic) for a given grade. The shaded area in the schematic probability distribution for holding force represents the probability that the inequality in equation (9) has been violated. In this paper, this probability is called the probability of motion, $p_{m}$. The distribution of the holding force shifts along the horizontal axis as the number of cars with hand brakes and the number of chocked wheels are varied for a constant cut of cars on a given grade. The probability of motion will decrease as the number of hand brakes applied and/or blocked wheels increases.

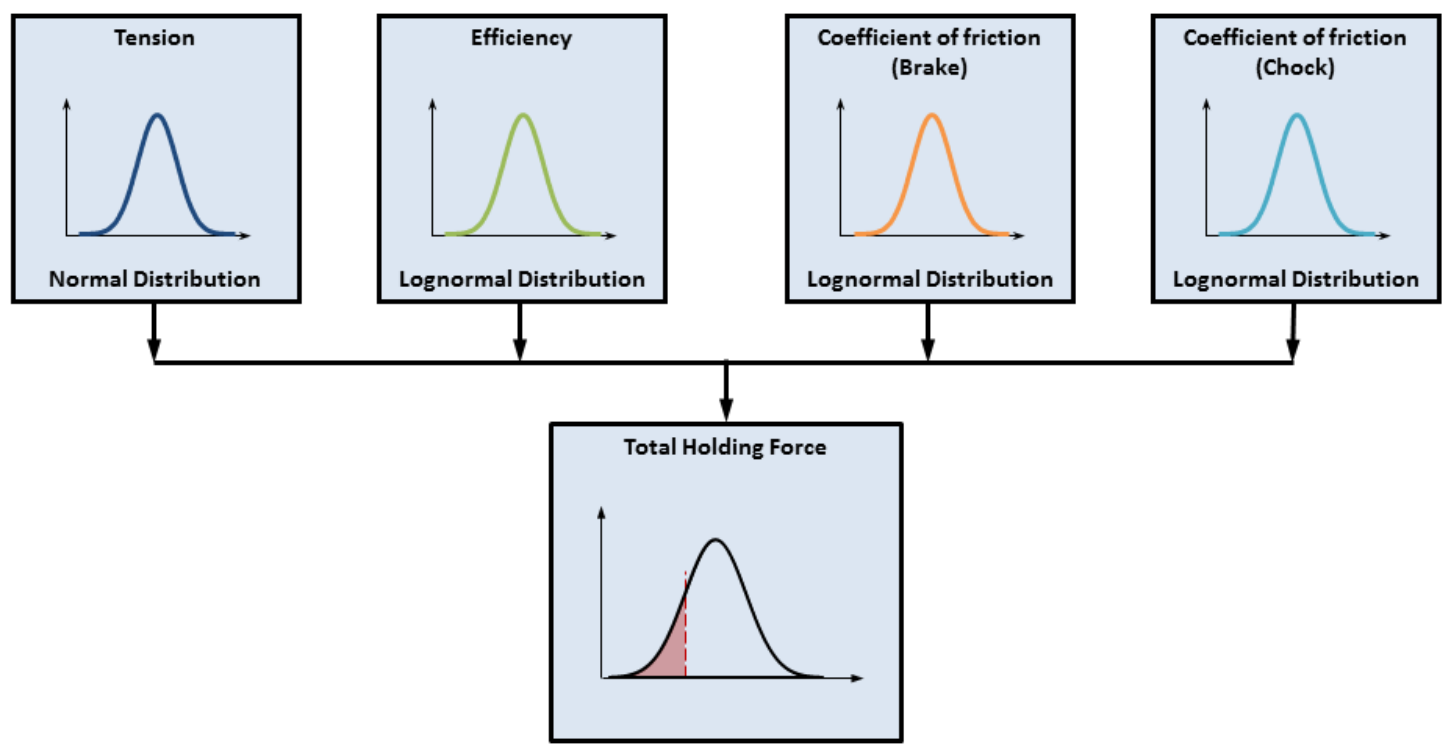

Figure 3: Schematic of Monte Carlo Model 
The tension in the chain of the handbrake can be influenced by the size of the person setting the brake, the functioning of the handbrake wheel, and the position and effort of the person setting the brake. For example, one railroad does not allow its car men to mount the end platform to set the brake for safety reasons. Instead they use a pole with a clamping mechanism to turn the handbrake wheel. The torque applied to the wheel by one of these car men will be less than if they were permitted to stand on the end platform to set the brake. A normal probability distribution is assumed for the tension in the hand brake chain.

The variance (i.e. standard deviation) of the coefficient of friction for the brake pad is assumed to be relatively small because the pad and wheel material are homogeneous and their interaction is well understood. Moreover, the brake pad is designed to maintain a nearly constant coefficient of friction throughout its operational life.

A chock is usually a simple wedge made of steel or wood. The coefficient of friction between the rail and chock was assumed to be that of wood and steel. The range of values was based on the potential for moisture on the rail.

A detailed treatment of the nature of frictional forces should include the effects of environmental conditions (e.g. humidity and temperature) and surface conditions (e.g. cleanliness). Such studies, however, are beyond the scope of the present work. Without data or evidence to suggest differently, Steele [5] recommends that a lognormal distribution should be allocated for the coefficients of friction and wear. In addition, assuming a lognormal distribution eliminates the possibility of negative values, which is theoretically possible if a Gaussian or normal distribution is assumed.

The ease of movement of the linkages and levers of the handbrake systems can be affected by debris, rust, wear and tear, and frequency of use. Assigning a representative value to the efficiency of the system is difficult to quantify and, therefore, a relatively large variance is assumed. Moreover, the efficiency of the linkage system is modeled by a lognormal distribution to avoid the possibility of negative values, as mentioned previously.

\section{NUMERICAL SIMULATIONS}

A computer code was written in Fortran to generate random numbers for the discrete random variables in the Monte Carlo simulations. In order to develop the probability density function for the total holding force, as shown in Figure 3, the Monte Carlo model was exercised for several thousands of simulations for each case considered. For example, Figure 4 shows the effect of varying the number of Monte Carlo simulations on the estimated probability of movement for the case where five tank cars are parked on a $1.0 \%$ grade in which one car has its hand brakes set and two wheels are chocked. In theory, the error of calculations in Monte Carlo simulations decreases as the number of simulations increases. In practice, the Monte Carlo model was exercised for 100,000 simulations for each case presented in this paper.

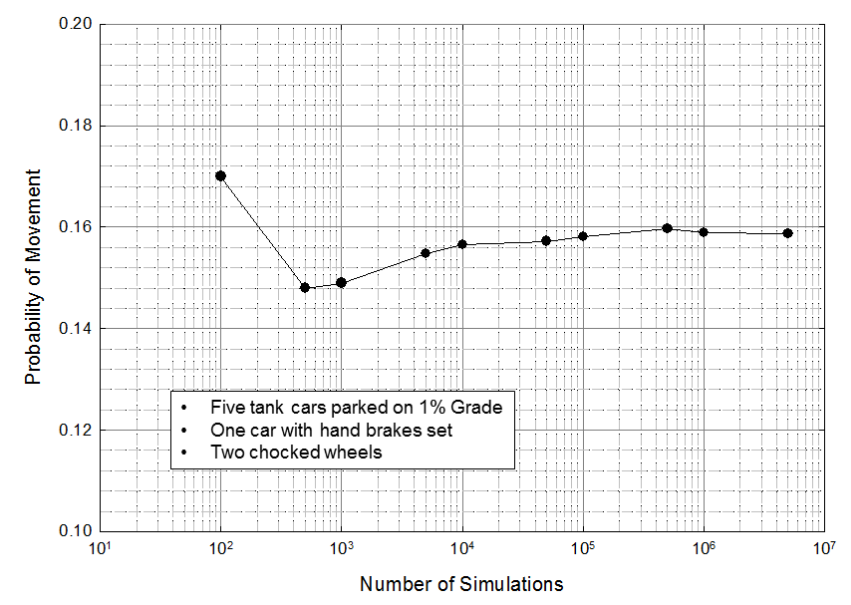

Figure 4: Probability of Movement for Varying Number of Simulations

Figure 5 displays results from exercising the Monte Carlo model for several cases of tank cars staged on a $1.0 \%$ grade. The axes on the horizontal plane are the number of tank cars on staged the grade and the number of tank cars with their hand brakes applied, both of which vary between one and ten. Thus, the figure shows results for a total of 55 cases. For each case, the number of chocked wheels is constant and equal to two. The vertical axis is the probability that the cut of cars will move down the grade from insufficient holding force. For example, in the cases where five tank cars parked on a $1.0 \%$ grade, the Monte Carlo approach estimates a zero probability of movement if four to five cars have their hand brakes applied. If one to three cars have their hand brake applied, a finite probability (i.e. probability greater than zero) exists that the cars will move. The probability increases as the number of cars with their hand brakes applied decreases (from less than $0.1 \%$ for three cars to about $16 \%$ for one car). In the cases where ten cars are parked on the grade, even if all ten cars have their hand brakes set, this method estimates a probability of movement equal to almost $50 \%$. Moreover, the figure shows that a probability greater than zero exists in 44 of the 55 cases.

The results displayed in Figure 6 are similar to those in the previous figure, except that the weight of all of the tank cars is equal to 263,000 $\mathrm{lb}$ for all cases. The probabilities in this set of results are lower than those shown in the previous figure. For example, in the case of ten cars parked on the grade and all cars with their hand brakes set, the estimated probability of movement is slightly more than $28 \%$ (compared to almost $50 \%$ in the previous figure). Moreover, these results suggest that assuming the maximum gross rail weight of 286,000 $\mathrm{lb}$ for all tank cars staged on the grade is a worst-case scenario. 


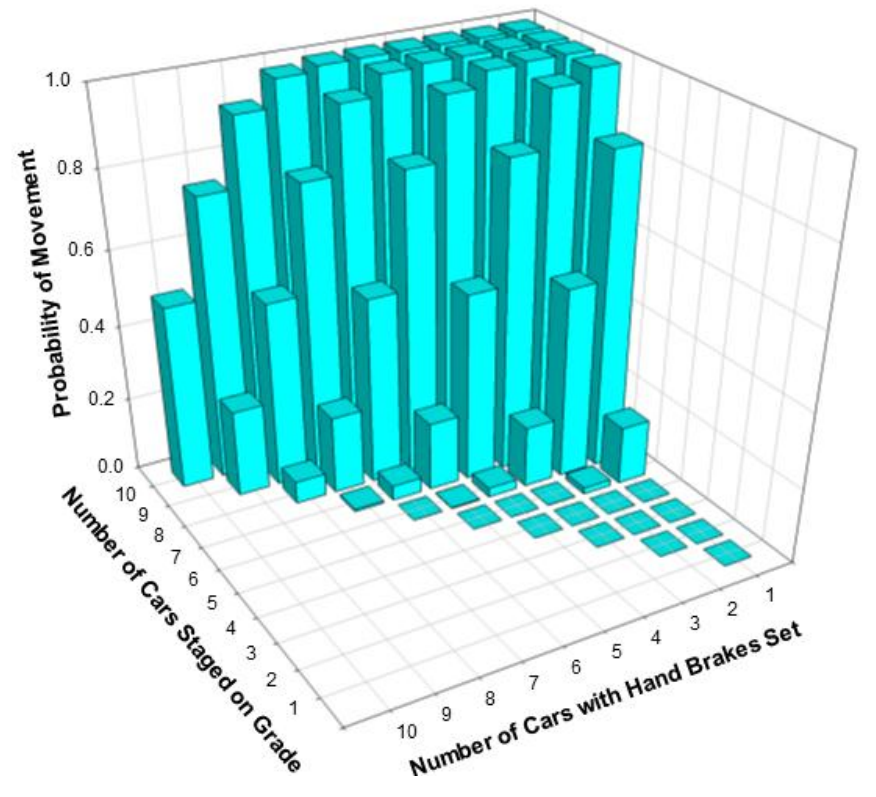

Figure 5: Probability of Movement for Tank Cars on 1.0\% Grade, All Cars Weigh 286 kips and 2 Wheels Chocked

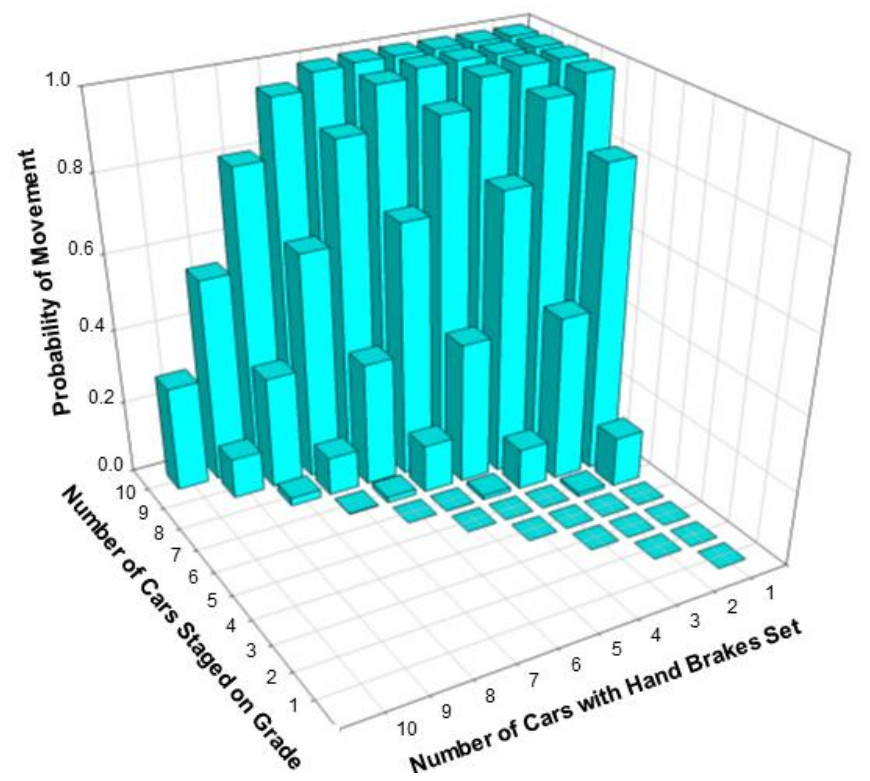

Figure 6: Probability of Movement for Tank Cars on 1.0\% Grade, All Cars Weigh 263 kips and 2 Wheels Chocked

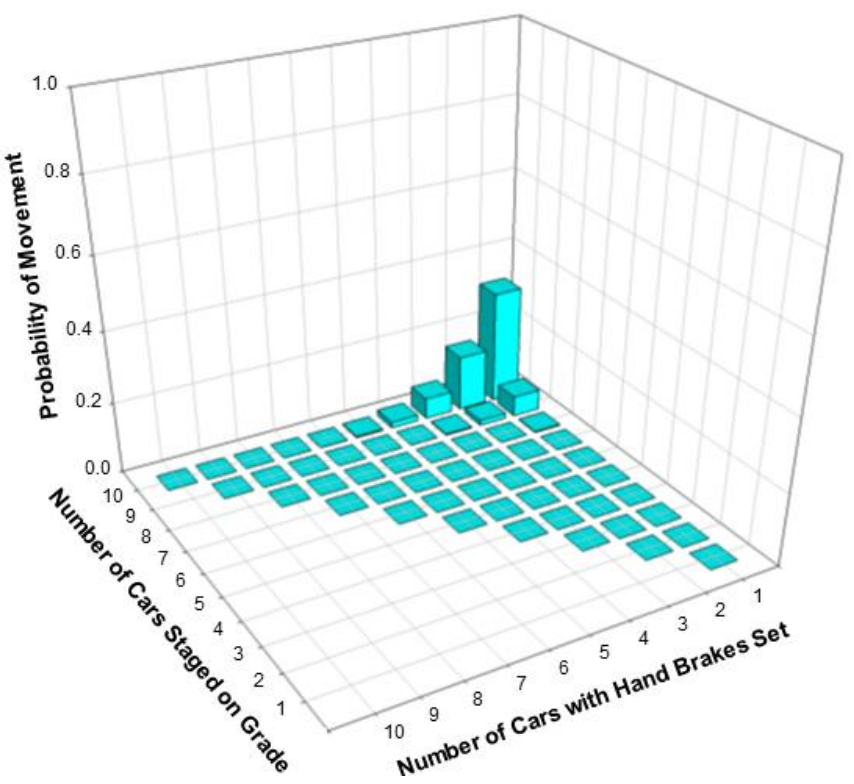

Figure 7: Probability of Movement for Tank Cars on 1.0\% Grade, All Cars Weigh 286 kips and 4 Wheels Chocked

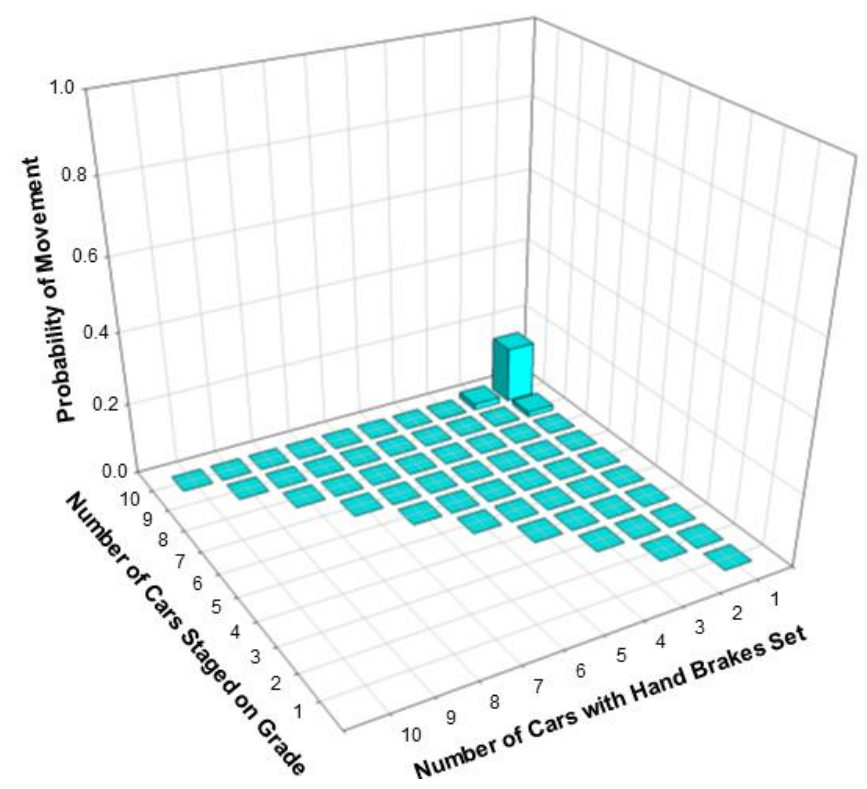

Figure 8: Probability of Movement for Tank Cars on $0.5 \%$ Grade, All Cars Weigh 286 kips and 2 Wheels Chocked 
Figure 7 shows results from the Monte Carlo simulations when four wheels are chocked instead of two. In this set of results, all of the tank cars weigh 286,000 lb. By blocking two additional wheels, these results indicate that the probability of movement is zero for 38 of the 55 cases. In the cases where ten cars are parked on the grade, the analysis estimates a zero probability of movement if eight to ten cars with their hand brakes set. The effect of chocked wheels in terms of the coefficient of friction is examined in the probabilistic sensitivity analysis.

Monte Carlo results for tank cars weighing $286,000 \mathrm{lb}$ on a $0.5 \%$ grade and two chocked wheels are illustrated in Figure 8. In these results, the probability of movement is estimated to be zero in 49 of the 55 cases. Furthermore, in three of the six cases with finite probability of movement, the estimated probability is less than one percent. These results suggest that the slope of the inclined plane, which is treated as a deterministic factor in the Monte Carlo approach described in this paper, has a strong effect on the probability of movement.

\section{Probabilistic Sensitivity}

Three measures of probabilistic sensitivity are calculated: (1) probabilistic importance factor, (2) probabilistic sensitivity with respect to changes in the mean value, and (3) probabilistic sensitivity with respect to changes in the standard deviation. The probabilistic importance factor is estimated using an advanced first-order second-moment method [6]. The latter two measures of probabilistic sensitivity are described in [7 and 8]. The calculations for the probabilistic sensitivity analysis are carried out using Mathcad, which is commercially available computer software for engineering calculations [9]. The same approach and the same measures of probabilistic sensitivity were used in a previous paper to examine the relative effect of various factors on the conditional probability of release of hazardous materials from railroad tank cars during accidents [3]. Moreover, the details of the probabilistic sensitivity analysis are described in the appendix of the previous paper.

Results from the analysis are shown in Figure 9, Figure 10, and Figure 11 for the three different measures of probabilistic sensitivity. The lengths of the bars in these figures indicate the relative effect of each random variable on the probability of impending motion. Moreover, each measure of probabilistic sensitivity indicates that the coefficient of friction for the chocked wheel has the most significant effect on securing the cut of cars on a grade.

Of the four factors considered in this probabilistic sensitivity study described in this paper, the coefficient of friction for the chocked wheel is shown to have the most significant effect on securing a cut of fully-loaded tank cars parked on a $1.0 \%$ grade. The significant effect of the coefficient of friction for chocked wheels is logical given the comparison of results shown previously in Figure 5 and Figure 7 , which compare the effect of the number of blocked wheels.

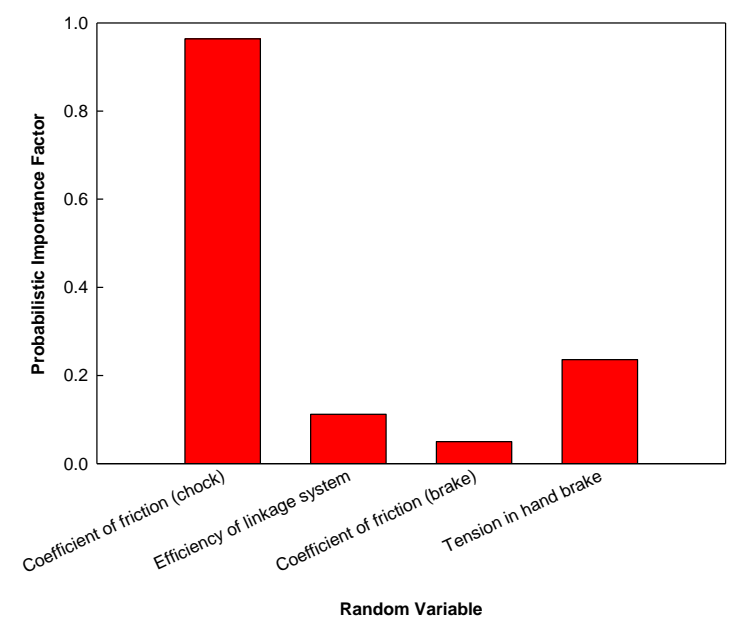

Figure 9: Probabilistic Importance Factor

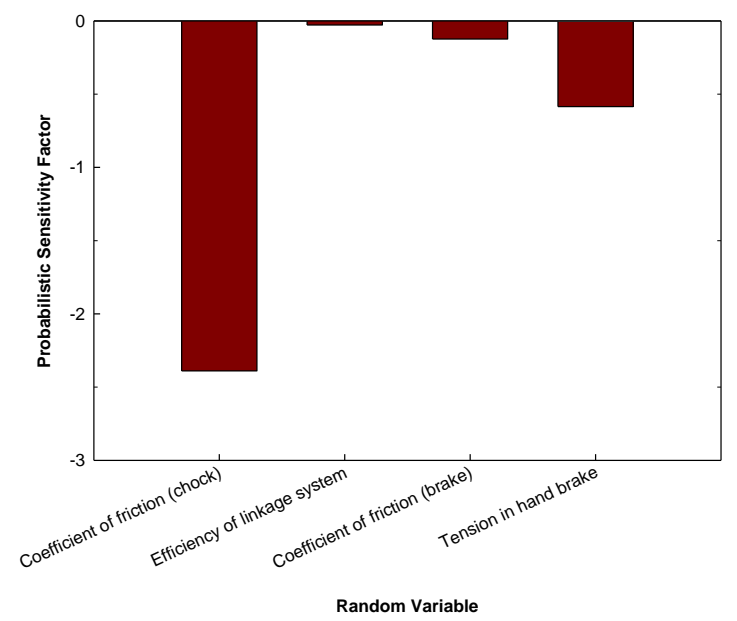

Figure 10: Probabilistic Sensitivity with Respect to Changes in Mean

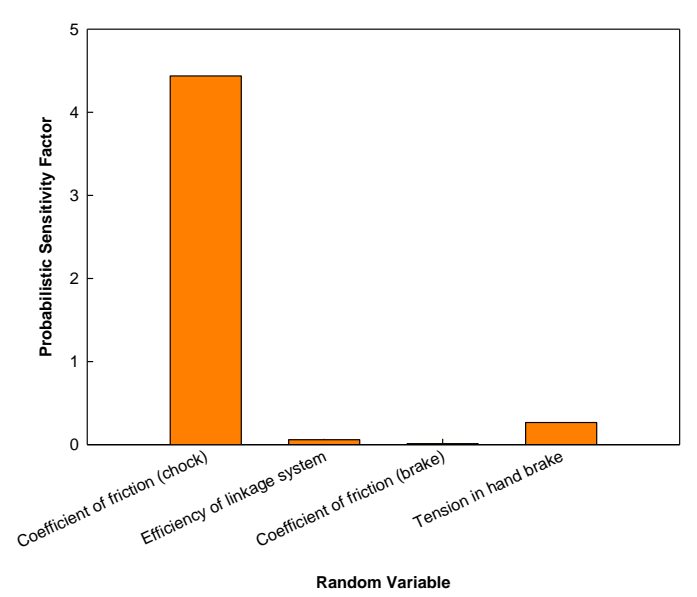

Figure 11: Probabilistic Sensitivity with Respect to Changes in Standard Deviation 
In terms of ranking, all three measures of probabilistic sensitivity indicate that the tension in the hand brake is the second most significant factor. The relative ranking of the remaining two factors is different depending on the probabilistic sensitivity metric. For instance, the probabilistic importance factor and the probabilistic sensitivity with respect to changes in the standard deviation suggest that the efficiency of the linkage system has a greater effect on securing the parked cars than the coefficient of friction for the hand brake. Conversely, the probabilistic sensitivity with respect to changes in the mean suggest that the coefficient of friction for the hand brake affects securement more than the efficiency of the linkage system. The effect of these two factors, however, is relatively small compared to that of the coefficient of friction for the chocked wheel.

\section{DISCUSSION}

The numerical procedure described in this paper to examine the holding forces needed to secure a segment of tank cars staged on a grade during loading and unloading operations included two types of factors: deterministic and probabilistic. The relative effects of the two types of factors were examined in different ways. The effect of the deterministic factors on the probability of movement was shown through numerical simulations, the results from which were displayed in the form of three-dimensional bar graphs. The effect of the probabilistic factors was examined through different measures of probabilistic sensitivity.

In general, results from a probabilistic sensitivity analysis will be different than results from a deterministic sensitivity analysis. This is because the deterministic sensitivities - which measure the change in model response for a given change in model input - do not account for uncertainty associated with each model input. Consequently, what is identified as being unimportant in a deterministic sensitivity analysis may in fact be very important when uncertainties are taken into account, as was done in this analysis. However, the reverse may also be true.

In a deterministic sensitivity analysis, baseline values are assumed to represent average or typical values for each factor. Each factor is then varied one at a time while holding the other factors equal to their baseline values to calculate the total holding force.

The effect of tank car weight $(286,000 \mathrm{lb}$ versus 263,000 lb) on the probability of movement was shown to be relatively minor. However, the number of tank cars parked on the grade, the number of tank cars with hand brakes applied, the number of chocked wheels, and the grade itself (i.e. slope of the inclined plane) were shown to have major effects.

In the probabilistic sensitivity analysis, the coefficient of friction for the chocked wheels was shown in each of the three different measures to have the most significant effect of the probability of movement.

\section{CONCLUDING REMARKS}

This paper describes an approach to determine the number of emergency brake systems that must be set in order to secure a segment of a train staged on a grade during loading and unloading operations of railroad tank cars carrying hazardous materials. Engineering mechanics are applied to derive equations to determine conditions of static equilibrium of objects resting on an inclined plane. These objects represent individual cars parked on a grade. The equations include factors such as tension in the hand brake chain and coefficients of friction, which have inherent uncertainties in estimating their real values. The Monte Carlo simulation technique is used to study these uncertainties. In addition, the relative effects of the various factors included in the equations for static equilibrium are examined via probabilistic sensitivity analysis. The probabilistic sensitivity analysis indicates that the coefficient of friction of the chocked wheel is the factor that has the most significant effect on securing a segment of cars parked on a $1.0 \%$ grade.

Based on the results presented in this paper, the number of cars with hand brakes applied depends on the total number of cars as well as the grade. Moreover, it is recommended that standard procedures be developed to limit the variability in hand brake tension which will in turn limit the number of hand brakes to be set.

\section{NOMENCLATURE}

$f_{b} \quad$ hand brake force per car

$f_{c} \quad$ chock force per wheel

$f_{w} \quad$ gravitational force parallel to slope per car

$F_{h} \quad$ total holding force

$F_{w} \quad$ total gravitational force parallel to slope

$m \quad$ number of choked wheels

$n \quad$ number of cars with hand brakes set

$N \quad$ number of cars on grade

$p_{m} \quad$ probability of motion

$T_{c} \quad$ hand brake chain tension

$W \quad$ tank car weight

$\varepsilon \quad$ efficiency of linkage system

$\mu_{b} \quad$ coefficient of friction (brake pad)

$\mu_{c} \quad$ coefficient of friction (chocked wheels)

$\mu_{s} \quad$ coefficient of static friction

$\theta \quad$ slope of grade in radians

\section{ACKNOWLEDGMENTS}

The work described in this paper was sponsored by the Federal Railroad Administration (FRA), Office of Research and Development. Mr. Kevin Kesler is the Chief of the Equipment and Operating Practices Division.

Technical discussions with Dr. Benjamin Perlman of the Volpe National Transportation Systems Center are gratefully acknowledged. 


\section{REFERENCES}

1. Code of Federal Regulations, Title 49 - Transportation, Part 179 - Carriage by Rail, Subpart C - General Handling and Loading Requirements, Section 179.67 Tank car unloading, Pipeline and Hazardous Materials Administration, October 2009.

2. HM-233, "Applicability of the Hazardous Materials Regulations to Loading, Unloading, and Storage," Federal Register Vol. 70, No. 72, April 15, 2005, pp. 2001820034.

3. Jeong, D.Y., "Probabilistic approach to conditional probability of release of hazardous materials from railroad tank cars during accidents," Proceedings of the 2009 ASME International Mechanical Engineering Congress and Exposition, November 2009.

4. Haldar, A., Mahadevan, S., Probability, Reliability and Statistical Methods in Engineering Design, John Wiley \& Sons, 2000.
5. Steele, C., "Use of lognormal distribution for coefficients of friction and wear," Reliability Engineering \& System Safety 93, October 2008, pp. 1574-1576.

6. Ayyub, B.M., McCuen, R.H., Probability, Statistics \& Reliability for Engineers, CRC Press, 1997.

7. $\mathrm{Wu}, \mathrm{Y} . \mathrm{T}$., "Computational methods for efficient structural reliability and reliability sensitivity analysis," AIAA Journal 32, August 1994, pp. 1717-1723.

8. Mohanty, S., Wu, Y.T., "CDF sensitivity analysis technique for ranking influential parameters in the performance assessment of the proposed high-level waste repository at Yucca Mountain, Nevada, USA," Reliability Engineering and System Safety 73, August 2001, pp. 167176.

9. $\quad$ http://www.ptc.com/products/mathcad/ 